\title{
Unit per Hour
}

National Cancer Institute

\section{Source}

National Cancer Institute. Unit per Hour. NCI Thesaurus. Code C66970.

An arbitrary unit of substance rate expressed in unit(s) per period of time equal to sixty minutes. 